\title{
Cardiorespiratory Fitness and Physical Activity following Lung Transplantation: A National Cohort Study
}

\author{
Mariann Ulvestad ${ }^{a, b} \quad$ Michael Thomas Durheim ${ }^{a, b} \quad$ Johny Steinar Kongerud ${ }^{a, b}$ \\ Bjørge Herman Hansen ${ }^{c}$ May Brit Lund ${ }^{a, b}$ Elisabeth Edvardsen ${ }^{\text {d, e }}$

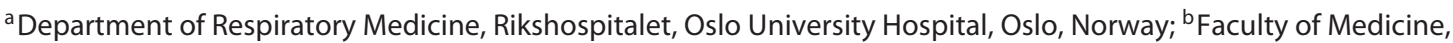

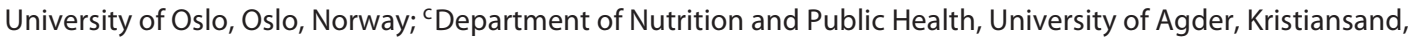 \\ Norway; ${ }^{\mathrm{d} D e p a r t m e n t}$ of Sports Medicine, Norwegian School of Sport and Sciences, Oslo, Norway; ${ }^{\text {eDepartment of }}$ \\ Pulmonary Medicine, Ullevål, Oslo University Hospital, Oslo, Norway
}

\author{
Keywords \\ Lung transplantation - Cardiopulmonary exercise testing . \\ Physical activity · Respiratory physiology · Exercise \\ physiology
}

\begin{abstract}
Background: Low cardiorespiratory fitness and inactivity are common after lung transplantation (LTX). The causes of exercise intolerance are incompletely understood. Objectives: The aim of this study was to objectively assess cardiorespiratory fitness and physical activity, evaluate causes of exercise intolerance, and explore clinical factors associated with cardiorespiratory fitness after bilateral LTx (BLTx). Materials and Methods: Peak oxygen uptake $\left(\dot{\mathrm{V}}_{2 \text { peak }}\right)$ and exerciselimiting factors were evaluated by a treadmill cardiopulmonary exercise test (CPET) 6-60 months after BLTx. Physical activity was measured with accelerometers, and results were compared with Norwegian normative data and the World Health Organization's (WHO) recommendations for physical activity. Results: In 54 included BLTx recipients (mean age 50
\end{abstract}

\pm 15 years, $50 \%$ females), $\dot{\mathrm{V}}_{2 \text { peak }}\left(\mathrm{mL} \times \mathrm{kg}^{-1} \times \mathrm{min}^{-1}\right)$ was $21.8 \pm 7.7$ for men and $22.4 \pm 6.2$ for women, corresponding to $57 \pm 17$ and $70 \pm 12 \%$ of predicted, respectively. Three patients $(6 \%)$ met criteria for normal $\dot{\mathrm{V}}_{2 \text { peak. }}$. Deconditioning limited $\dot{\mathrm{V}} \mathrm{O}_{2 \text { peak }}$ in 22 patients $(41 \%)$, while ventilatory limitation and abnormal gas exchange were observed in 14 (26\%) and 20 (37\%) patients, respectively (some had more than 1 finding). Forty-three patients (86\%) did not meet the WHO physical activity recommendations. There was a moderate correlation between $\dot{\mathrm{V}}_{2 \text { peak }}$ and physical activity $(r=0.642$, $p<0.01)$. Body mass index, physical activity, forced expiratory volume after 1 second, sex, and hemoglobin together accounted for $73 \%$ of the variability in $\dot{\mathrm{V}}_{2 \text { peak. }}$. Conclusions: Low cardiorespiratory fitness was observed in the majority of BLTx recipients. Both deconditioning and cardiopulmonary limitations were common findings. Nearly $90 \%$ were classified as being inactive according to physical activity recommendations. CPET appears to identify a deconditioned subgroup of BLTx recipients for whom exercise training may be especially beneficial.

(c) 2020 The Author(s) Published by S. Karger AG, Basel

$\begin{array}{ll}\text { karger@karger.com } & \text { (c) 2020 The Author(s) } \\ \text { Published by S. Karger AG, Basel } & \text { Karger } \\ \text { This article is licensed under the Creative Commons Attribution- } & \text { NonCommercial-NoDerivatives 4.0 International License (CC BY- } \\ \text { NC-ND) (http://www.karger.com/Services/OpenAccessLicense). } \\ \text { Usage and distribution for commercial purposes as well as any dis- } \\ \text { tribution of modified material requires written permission. }\end{array}$

Mariann Ulvestad, MD

Department of Respiratory Medicine Oslo University Hospital

$\mathrm{Pb} 4950$ Nydalen, NO-0424 Oslo (Norway) mulves@ ous-hf.no 


\section{Introduction}

Lung transplantation (LTx) is a well-established lifesaving treatment for patients with end-stage lung disease, with nearly 5,000 transplants performed each year worldwide [1]. Exercise intolerance often persists for several years following LTx, despite success of the surgical procedure and improved lung function [2]. The causes of exercise intolerance in this population are incompletely understood.

In the general population, cardiorespiratory fitness is reported to be a stronger predictor of mortality than wellacknowledged risk factors, such as hypertension, smoking, obesity, hyperlipidemia, and diabetes [3, 4], and is also associated with cardiovascular morbidity and healthrelated quality of life (HRQoL) [5]. As many as 30-50\% of LTx recipients develop comorbid conditions, such as diabetes and hyperlipidemia, in the years after transplantation, and the majority are diagnosed with hypertension by 5 years after transplant [1]. Thus, cardiorespiratory fitness in this vulnerable LTx population is potentially an important factor related to overall health and delaying lifestyle diseases and mortality. While a number of studies have measured cardiorespiratory fitness in LTx recipients, the majority were performed in an earlier era of LTx (in the 1990s) [6-10] or are limited by small sample sizes $(n<25)$ [6-12]. While physical activity is known to be reduced among LTx recipients both before and after transplant [2], the relationship between physical activity and cardiorespiratory fitness in this population is not well established. Finally, it is unclear which demographic and clinical factors influence cardiorespiratory fitness after LTx.

In this cross-sectional study, we aimed to determine cardiorespiratory fitness and level of physical activity in a nationwide cohort of bilateral LTx (BLTx) recipients. Further, we aimed to identify causes of exercise intolerance, study the relationship between cardiorespiratory fitness and physical activity, and explore clinical factors that may be associated with peak oxygen uptake $\left(\dot{\mathrm{V}}_{2 \text { peak }}\right)$ after LTx.

\section{Materials and Methods}

\section{Study Population}

In this national cohort study, BLTx recipients were recruited at Oslo University Hospital between August 2017 and June 2018. In Norway, all organ transplantations are performed in 1 center, which serves the entire Norwegian population of approximately 5.3 million. Since 2012, only BLTx, and no single LTx, has been performed.

Cardiorespiratory Fitness after Lung

Transplantation
Eligible patients were $\geq 18$ years of age with stable condition 6 months to 5 years after BLTx. The patients were classified as "stable" if their pulmonary function had not changed precipitously (defined as a reduction in forced expiratory volume after 1 second $\left[\mathrm{FEV}_{1}\right]>10 \%$ ) over the past 6 months and if they did not have any other acute and/or function-limiting conditions under ongoing treatment in the opinion of the treating pulmonologist. Patients were not eligible if they could not communicate in Norwegian or were unable to walk on a treadmill until exhaustion due to musculoskeletal conditions. All patients received triple-drug immunosuppression (tacrolimus or cyclosporine, mycophenolate mofetil, and corticosteroids) except 1 who did not take mycophenolate mofetil due to leukopenia. All BLTx recipients at our institution start postoperative physical therapy as soon as medically advisable. During the hospital stay - usually lasting 4-6 weeks - they have daily sessions with a physical therapist. After discharge, the patients are referred to local physical therapists. Most patients attend sessions 1-2 times per week for up to 6 months. Patients who need more intensive training are referred to a 4 -week inpatient program at a national facility for cardiopulmonary rehabilitation. After 6 months, the patients are encouraged to maintain regular physical activity at their own discretion. Written informed consent was obtained from all patients prior to enrollment. Ethical approval was obtained from the Regional Committee for Medical and Health Research Ethics (REK South-East, No. 2017/399).

\section{Clinical Characteristics}

Data on native lung disease, time since BLTx, comorbidities, and medications were obtained from the patients' medical records. Registered comorbidities included anemia, renal dysfunction, arterial hypertension, diabetes, and overweight. Anemia was defined as a hemoglobin concentration $(\mathrm{Hb})<13 \mathrm{~g} \times \mathrm{dL}^{-1}$ for men and $<12 \mathrm{~g} \times \mathrm{dL}^{-1}$ for women. Moderate anemia was defined as $\mathrm{Hb}<11$ and $<10 \mathrm{~g} \times \mathrm{dL}^{-1}$ and severe anemia as $\mathrm{Hb}<8$ and $<7 \mathrm{~g} \times \mathrm{dL}^{-1}$ for men and women, respectively [13]. Renal dysfunction was defined as an estimated glomerular filtration rate $<60 \mathrm{~mL} \times \mathrm{min}^{-1} \times 1.73$ $\mathrm{m}^{-2}$ in accordance with local reference values. Hypertension was defined as the use of antihypertensive drugs, and diabetes was defined as the use of antidiabetic drugs. Overweight was defined as a body mass index (BMI) $\geq 25 \mathrm{~kg} \times \mathrm{m}^{-2}$, and obesity was defined as a BMI $\geq 30 \mathrm{~kg} \times \mathrm{m}^{-2}$, in line with the World Health Organization (WHO) classification [14]. Chronic lung allograft dysfunction (CLAD) was defined as a persistent decline in $\mathrm{FEV}_{1}$ of $20 \%$ from the mean of the 2 highest posttransplant values in the absence of other explanatory conditions [15].

\section{Pulmonary Function Tests}

Pulmonary function was assessed by spirometry and diffusing capacity of the lungs for carbon monoxide $\left(\mathrm{DL}_{\mathrm{CO}}\right.$; Jaeger Master Screen Body, Eric Jaeger, Wurzburg, Germany) in accordance with the recommendations of the ATS/ERS task force [16, 17]. Reference values were calculated using the Global Lung Function Initiative equations $[18,19]$.

\section{Cardiopulmonary Exercise Test}

Under guidance of an exercise physiologist and a physician, all patients performed a maximal symptom-limited cardiopulmonary exercise test (CPET) on a treadmill (TechnoGym Runrace, Forli, Italy) using a modified Balke protocol [20] that was also used for testing the reference population [21]. The speed was set to 1.8, 2.8, 
Table 1. Characteristics of the study population

\begin{tabular}{|c|c|c|c|}
\hline & Male $(n=27)$ & Female $(n=27)$ & All $(n=54)$ \\
\hline Age, years & $53.3 \pm 0.6$ & $50.0 \pm 14.5$ & $51.6 \pm 12.7$ \\
\hline $\mathrm{BMI}, \mathrm{kg} \times \mathrm{m}^{-2}$ & $26.9 \pm 4.3$ & $25.4 \pm 3.8$ & $26.1 \pm 4.1$ \\
\hline Hemoglobin, $\mathrm{g} \times \mathrm{dL}^{-1}$ & $13.0 \pm 1.5$ & $11.8 \pm 1.2$ & $12.4 \pm 1.5$ \\
\hline Time after BLTx, months & $30 \pm 16$ & $27 \pm 16$ & $28 \pm 16$ \\
\hline History of smoking & $11(41)$ & $17(63)$ & $28(52)$ \\
\hline CLAD & $6(22)$ & $1(4)$ & $7(13)$ \\
\hline Use of $\beta$-blockers & $5(19)$ & $6(22)$ & $11(20)$ \\
\hline \multicolumn{4}{|l|}{ Comorbidities } \\
\hline Anemia & $14(52)$ & $13(48)$ & $27(50)$ \\
\hline Arterial hypertension & $13(48)$ & $9(33)$ & $22(41)$ \\
\hline Diabetes & $1(4)$ & $1(4)$ & $2(4)$ \\
\hline Renal dysfunction & $12(44)$ & $14(52)$ & $26(48)$ \\
\hline \multicolumn{4}{|l|}{ Native lung disease } \\
\hline COPD & $11(41)$ & $13(48)$ & $24(44)$ \\
\hline Interstitial lung disease & $10(37)$ & $5(19)$ & $15(28)$ \\
\hline Cystic fibrosis & 0 & $2(7)$ & $2(4)$ \\
\hline Other & $6(22)$ & $7(26)$ & $13(24)$ \\
\hline \multicolumn{4}{|l|}{ Pulmonary function } \\
\hline FVC, L (\% of predicted) & $3.8 \pm 1.0(79 \pm 18)$ & $3.4 \pm 0.7(99 \pm 19)$ & $3.6 \pm 0.9(89 \pm 21)$ \\
\hline 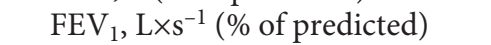 & $2.5 \pm 0.8(67 \pm 21)$ & $2.6 \pm 0.7(95 \pm 22)$ & $2.6 \pm 0.7(81 \pm 25)$ \\
\hline MVV, $\mathrm{L} \times \mathrm{min}^{-1}$ (\% of predicted) & $112.1 \pm 34.5(85 \pm 26)$ & $100.2 \pm 18.6(101 \pm 18)$ & $106.2 \pm 28.1(93 \pm 24)$ \\
\hline \multicolumn{4}{|l|}{$\mathrm{DL}_{\mathrm{CO}}, \mathrm{mmol} \times \mathrm{kPa}^{-1} \times \mathrm{min}^{-1}$} \\
\hline (\% of predicted) & $6.7 \pm 1.6(70 \pm 14)$ & $5.9 \pm 1.2(83 \pm 18)$ & $6.33 \pm 1.5(77 \pm 17)$ \\
\hline
\end{tabular}

Values are means \pm standard deviations or $n(\%)$. BLTx, bilateral lung transplantation; BMI, body mass index; CLAD, chronic lung allograft dysfunction; COPD, chronic obstructive pulmonary disease; $\mathrm{DL}_{\mathrm{CO}}$, diffusing capacity for carbon monoxide; $\mathrm{FEV}_{1}$, forced expiratory volume after 1 second; FVC, forced vital capacity; $\mathrm{Hb}$, hemoglobin concentration; MVV, maximum voluntary ventilation.

3.8 , or $4.8 \mathrm{~km} \times \mathrm{h}^{-1}$, depending on the patient's self-reported level of fitness and performance during familiarization with the treadmill prior to CPET. The inclination was set to $4 \%$ and increased by $2 \%$ every minute. If the patient reached the maximum inclination of $20 \%$, the speed was increased by $0.5 \mathrm{~km} \times \mathrm{h}^{-1}$ every minute until exhaustion. Gas exchange and exhaled volumes were directly measured breath-by-breath (Vyntus CPX Metabolic Cart, CareFusion Corporation, Höchberg, Germany). Prior to each test, the metabolic cart was calibrated for volume and gas according to the standards given by the manufacturer. The highest $\dot{\mathrm{V}} \mathrm{O}_{2}$ measured over $30 \mathrm{~s}$ was defined as $\dot{\mathrm{VO}}_{2 \text { peak. }}$. Percutaneous oxygen saturation $\left(\mathrm{SpO}_{2}\right)$ was measured with finger pulse oximeter (NONIN8600, Medical Inc., Minneapolis, MN, USA), and a 12-lead ECG (Custo cardio 100, CustoMed, Ottobrunn, Germany) was conducted for evaluation of ischemia and/or arrhythmias. After test termination, the rating of perceived exertion was assessed by the Borg scale $_{6-20}$. Postexercise blood lactate concentration was measured within $60 \mathrm{~s}$ of stopping to objectively assess the patient's effort [22].

Ventilatory threshold was determined by the ventilatory equivalent method [23]. Minute ventilation (VE) and carbon dioxide output $\left(\mathrm{VCO}_{2}\right)$ during CPET below the respiratory compensation point were used to calculate the $\mathrm{VE} / \mathrm{VCO}_{2}$ slope. Predicted $\dot{\mathrm{VO}} \mathrm{C}_{2 \text { peak }}$ and peak heart rate $\left(\mathrm{HR}_{\text {peak }}\right)$ were calculated based on equations from Edvardsen et al. [21].
The definition of maximal effort was a high respiratory exchange ratio (1.0-1.10) and lactate concentration $(\geq 3.5-9 \mathrm{mmol} \times$ $\left.\mathrm{L}^{-1}\right)$ relative to age and gender in accordance with the recommendations by Edvardsen et al. [22]. Low cardiorespiratory fitness was defined as $\dot{\mathrm{VO}_{2 p e a k}}<85 \%$ of predicted, ventilatory limitation as breathing reserve $<15 \%$ or $<11 \mathrm{~L} \times \mathrm{min}^{-1}$, exercise-induced hypoxemia as $\mathrm{SpO}_{2}<88 \%$, and signs of ventilation perfusion (VQ) mismatch (gas exchange limitation) were defined as a $\mathrm{VE} / \mathrm{VCO}_{2}$ slope $\geq 34$ [24]. Poor chronotropic response was defined as a $\mathrm{HR}<80 \%$ of predicted in the absence of pulmonary limitations [25]. Deconditioning was defined as low cardiorespiratory fitness in the absence of cardiopulmonary limitations.

\section{Accelerometer}

For objective assessment of physical activity, all patients were asked to carry an accelerometer (ActiGraph GT1M, LLC, Pensacola, FL, USA) for 7 consecutive days during waking hours, except during water-based activities. The accelerometer registered vertical accelerations in counts per minute and number of steps per day. Moderate-to-vigorous physical activity was defined as all activity $\geq 2,020$ counts per minute (equivalent to 3 metabolic equivalents of task) occurring in bouts lasting for at least $10 \mathrm{~min}[26,27]$. Adherence to physical activity recommendations was defined as accumulating a daily average of moderate-to-vigorous physical activity accrued in bouts $>21.4 \mathrm{~min} /$ day in accordance with WHO 
Table 2. Cardiopulmonary response during cardiopulmonary exercise testing in bilateral lung transplant recipients

\begin{tabular}{|c|c|c|c|}
\hline & $\operatorname{Men}(n=27)$ & Women $(n=27)$ & All $(n=54)$ \\
\hline$\dot{\mathrm{VO}}_{2 \text { peak }}, \mathrm{mL} \times \mathrm{kg}^{-1} \times \mathrm{min}^{-1}(\%$ of predicted $)$ & $21.8 \pm 7.7(57 \pm 17)$ & $22.4 \pm 6.2(70 \pm 12)$ & $22.1 \pm 6.9(64 \pm 16)$ \\
\hline$\dot{\mathrm{V}} \mathrm{O}_{2 \text { peak }}, \mathrm{L} \times \mathrm{min}^{-1}(\%$ of predicted) & $1.78 \pm 0.49(55 \pm 13)$ & $1.51 \pm 0.24(69 \pm 11)$ & $1.65 \pm 0.41(62 \pm 14)$ \\
\hline $\mathrm{VT}, \mathrm{L} \times \mathrm{min}^{-1}$ (\% of predicted) & $1.41 \pm 0.39(62 \pm 15)$ & $1.18 \pm 0.20(72 \pm 12)$ & $1.28 \pm 0.32(67 \pm 14)$ \\
\hline Peak ventilation, $\mathrm{L} \times \mathrm{min}^{-1}$ (\% of predicted) & $78.6 \pm 22.8(68 \pm 18)$ & $67.48 \pm 15.4(85 \pm 17)$ & $73.0 \pm 20.1(77 \pm 20)$ \\
\hline Respiratory rate, breaths $\times \min ^{-1}$ & $38.6 \pm 6.9$ & $36.4 \pm 8.8$ & $37.5 \pm 7.9$ \\
\hline Breathing reserve, $\%$ & $27.9 \pm 14.2$ & $31.9 \pm 12.7$ & $29.9 \pm 13.5$ \\
\hline $\mathrm{VE} / \mathrm{VCO}_{2}$ slope & $35.6 \pm 10.5$ & $33.0 \pm 4.5$ & $34.3 \pm 8.1$ \\
\hline $\mathrm{HR}_{\text {peak }}$, beats $\times \min ^{-1}$ ( $\%$ of predicted $)$ & $145.3 \pm 17.1(84 \pm 9)$ & $155.7 \pm 19.2(89 \pm 9)$ & $150.5 \pm 18.8(86 \pm 9)$ \\
\hline $\mathrm{O}_{2}$-pulse, $\mathrm{mL} \times$ beat $^{-1}(\%$ of predicted $)$ & $12.2 \pm 2.7(67 \pm 14)$ & $9.8 \pm 1.5(80 \pm 14)$ & $11.0 \pm 2.5(73 \pm 15)$ \\
\hline Lowest $\mathrm{SpO}_{2}$ during test, $\%$ & $94(87-98)$ & $96(90-99)$ & $95(87-99)$ \\
\hline Borg scale $_{6-20}$ & $18.1 \pm 1.13$ & $18.3 \pm 0.9$ & $18.2 \pm 1.0$ \\
\hline Blood lactate, $\mathrm{mmol} \times \mathrm{L}^{-1}$ & $7.8 \pm 2.7$ & $8.7 \pm 2.1$ & $8.3 \pm 2.4$ \\
\hline Respiratory exchange ratio, $\mathrm{VCO}_{2} / \mathrm{VO}_{2}$ & $1.08 \pm 0.13$ & $1.15 \pm 0.07$ & $1.12 \pm 0.11$ \\
\hline
\end{tabular}

Data are presented as means \pm standard deviations or medians (ranges). $\mathrm{HR}_{\text {peak, }}$ peak heart rate; $\dot{\mathrm{VO}}_{2 \text { peak }}$, peak oxygen consumption; VT, ventilatory threshold; $\mathrm{SpO}_{2}$, peripheral capillary oxygen saturation.

recommendations [28]. Data was included if the patients had accumulated at least $10 \mathrm{~h}$ of activity recordings per day for a minimum of 2 days. The objectively measured physical activity was compared to normative values [26].

\section{Health-Related Quality of Life}

The 36-Item Short Form Health Survey (SF-36) was used to evaluate HRQoL. The SF-36 consists of 8 scales, which can be aggregated into 2 summary measures: the Physical and Mental Component Summary scores. The summary scores (scaled from 0 to 100) are based on data for the US general population standardized to a mean of 50 and SD of 10, where higher scores indicate better functioning [29].

\section{Statistics}

Descriptive data are presented as means \pm standard deviations or medians (ranges) as appropriate. Means for physical activity were compared to Norwegian standard values using a one-sample $t$ test, assuming the difference between BLTx recipients and the Norwegian standard would be equal to zero. A $p$ value of $<0.05$ was regarded as statistically significant. Pearson correlation coefficients were calculated between $\dot{\mathrm{V}} \mathrm{O}_{2 \text { peak }}$, physical activity level (counts per minute), time since transplantation, and SF-36 scores. A negligible correlation was defined as $<0.30$, a low correlation as $0.30-0.49$, a moderate correlation as $0.50-0.69$, a high correlation as $0.70-0.89$, and a very high correlation as $\geq 0.90$ [30].

To explore potential factors associated with cardiorespiratory fitness, univariate regression analyses were used, where $\dot{\mathrm{VO}}{ }_{2 \text { peak }}$ in $\%$ of predicted was set as the dependent variable. To identify the degree of association with $\dot{\mathrm{VO}}_{2 \text { peak }}$, the relevant variables with significant associations in univariate analyses $(p<0.05)$ and other clinical variables known to affect $\dot{\mathrm{V}}_{2 \text { peak }}$ (age, sex, $\mathrm{BMI}$, and $\mathrm{Hb}$ ) were selected for multiple regression analyses. The final model was built using a series of multiple regression analyses with the enter method. All analyses were performed using SPSS version 25.0 (IBM Statistics, Chicago, IL, USA).

Cardiorespiratory Fitness after Lung

Transplantation

\section{Results}

Of 73 patients assessed for eligibility, 16 declined participation and 3 could not be tested due to unstable health conditions. In total, 27 men and 27 women (mean age $50 \pm 15$, range $20-67$ years) were included in the study 6-59 months after BLTx. Clinical characteristics and pulmonary function are presented in Table 1. Twenty-two patients (41\%) had mild anemia and 5 patients (9\%) had moderate anemia. Twenty-seven patients (50\%) were overweight (BMI 25-29) and 9 (17\%) were obese (BMI >30). Seven patients, of whom 6 were men, had been diagnosed with CLAD prior to study enrollment (Table 1).

\section{Cardiorespiratory Fitness}

No adverse events were recorded during or after the CPET. Table 2 shows cardiopulmonary response during CPET. All but 2 patients reported exertion $\geq 17$ on the Borg scale at peak exercise. Fourteen patients did not reach the recommended age- and gender-adjusted endcriteria for lactate concentration and respiratory exchange ratio. Leg fatigue was the most frequent reason for stopping the CPET (46\%) followed by dyspnea (31\%) and general exhaustion (22\%).

Three patients (6\%) had normal cardiorespiratory fitness. Among the 51 patients (95\%) with low cardiorespiratory fitness, 14 patients (26\%) were ventilatory limited, 1 patient (2\%) had exercise-induced hypoxemia, and 20 
Fig. 1. Objectively measured physical activity expressed as counts per minute (a) and steps per day (b) (mean \pm SD) in 54 bilateral lung transplant recipients. The dotted line represents the Norwegian standard [26].
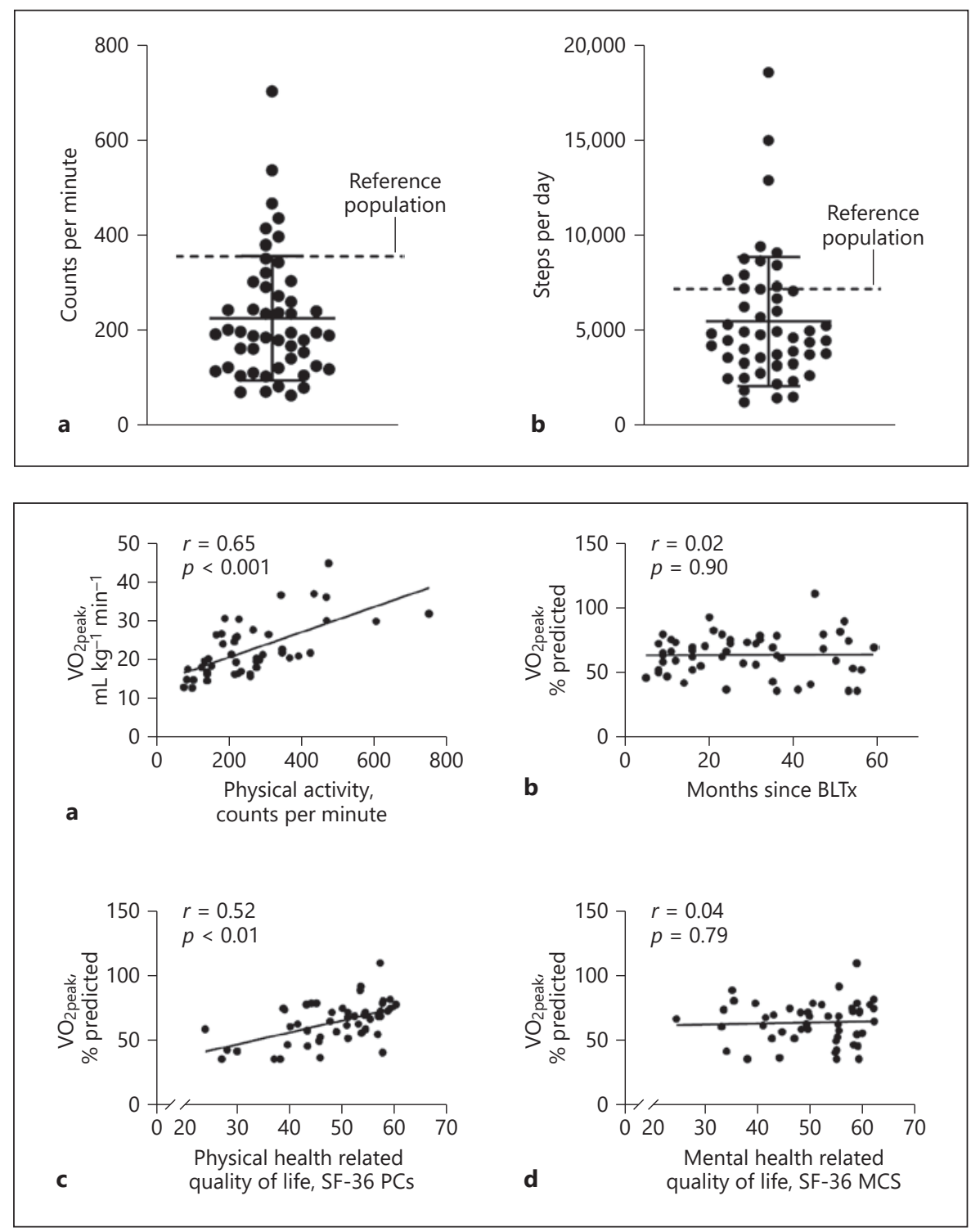

Fig. 2. a Correlation between $\dot{\mathrm{VO}}_{2 \text { peak }}(\mathrm{mL}$ $\times \mathrm{kg}^{-1} \times \mathrm{min}^{-1}$ ) and physical activity (counts per minute). b Correlation between peak oxygen uptake $\left(\dot{\mathrm{VO}}_{2 \text { peak }}\right)$ in percent of predicted and months since bilateral lung transplantation (BLTx). c, d Correlations between peak oxygen uptake $\left(\dot{\mathrm{VO}}_{2 \text { peak }}\right)$ in percent of predicted and SF-36 physical component summary score (SF36 PCS; c) and SF-36 mental component summary score (SF-36 MCS; d). Higher SF-36 score indicates better health-related quality of life.

\section{Physical Activity}

Fifty recipients (93\%) accumulated at least $10 \mathrm{~h}$ of valid activity recordings per day for at least 2 days. The mean accelerometer wear time was $15 \pm 2 \mathrm{~h}$ per day for $5.9 \pm 1.9$ days. Compared to the Norwegian national standard, BLTx recipients walked significantly fewer steps per day $(5,451 \pm 3,398$ vs. $8,241, p<0.001)$, had significantly fewer counts per minute $(226 \pm 131$ vs. $366, p<0.001$; Fig. 1$)$, and had $30 \%$ higher sedentary time $(p<0.001)$. Fortythree patients (86\%) were classified as physically inactive [28]. The 7 patients (14\%) meeting the WHO's physical activity recommendations had significantly higher $\dot{\mathrm{V}} \mathrm{O}_{2 \text { peak }}$ than those who did not ( $79 \pm 7$ vs. $62 \pm 15 \%$ of predicted, $p=0.001$ ). 
Table 3. Univariate and multiple regression analysis using $\dot{\mathrm{VO}}_{2 \text { peak }} \%$ of predicted as dependent variable in BLTx recipients $(n=54)$

\begin{tabular}{|c|c|c|c|c|}
\hline & \multicolumn{3}{|c|}{ Univariate regression analysis } & \multirow{2}{*}{$\begin{array}{l}\text { Multivariable regression } \\
\text { model }\left(R^{2}=0.726\right) \\
\text { unstandarized } \beta \\
(95 \% \mathrm{CI})\end{array}$} \\
\hline & $\begin{array}{l}\text { unstandarized } \beta \\
(95 \% \mathrm{CI})\end{array}$ & $R^{2}$ & $p$ value & \\
\hline Gender, female & $12.8(4.9$ to 20.7$)$ & 0.17 & 0.002 & $8.8(2.6$ to 14.9$)$ \\
\hline Age, years & $-0.3(-0.7$ to -0.01$)$ & 0.08 & 0.044 & $0.1(-0.2$ to 0.3$)$ \\
\hline $\mathrm{BMI}, \mathrm{kg} \times \mathrm{m}^{-2}$ & $-2.2(-3.1$ to $-1,3)$ & 0.35 & $<0.001$ & $-2.0(-2.9$ to -1.2$)$ \\
\hline Physical activity, counts per min & $0.08(0.04$ to 0.1$)$ & 0.33 & $<0.001$ & $0.05(0.03$ to 0.07$)$ \\
\hline Time since BLTx, years & $-0.2(-3.4$ to 3.0$)$ & $<0.001$ & 0.991 & \\
\hline SF-36 PCS & $0.9(0.5$ to 1.4$)$ & 0.27 & $<0.001$ & \\
\hline SF-36 MCS & $0.1(-0.4$ to 0.6$)$ & 0.002 & 0.788 & \\
\hline $\mathrm{FEV}_{1}, \%$ of predicted & $0.3(0.1$ to 0.4$)$ & 0.20 & 0.001 & $0.2(0.1$ to 0.3$)$ \\
\hline $\mathrm{DL}_{\mathrm{CO}}, \%$ of predicted & $0.4(0.2$ to 0.6$)$ & 0.21 & 0.001 & \\
\hline $\mathrm{Hb}, \mathrm{g} \times \mathrm{dL}^{-1}$ & $0.1(-2.8$ to 3.0$)$ & $<0.001$ & 0.923 & $2.8(0.9$ to 4.7$)$ \\
\hline Emphysema prior to BLTx & $-0.2(-8.9$ to 8.5$)$ & $<0.001$ & 0.960 & \\
\hline Renal insufficiency & $-3.8(-12.4$ to 4.7$)$ & 0.02 & 0.371 & \\
\hline Arterial hypertension & $-6.1(-14.7$ to 2.6$)$ & 0.04 & 0.165 & \\
\hline Use of $\beta$-blockers & $-8.9(-19.4$ to 1.5$)$ & 0.05 & 0.093 & \\
\hline
\end{tabular}

BLTx, bilateral lung transplantation; BMI, body mass index; $\mathrm{FEV}_{1}$, forced expiratory volume after 1 second; $\mathrm{DL}_{\mathrm{CO}}$, diffusing capacity; Hb, hemoglobin concentration; SF-36 MCS, 36-Item Short Form Health Survey Mental Component Summary Score; SF-36 Pcs, Short Form Health Survey Physical Component Summary Score.

\section{Associations with Cardiopulmonary Fitness}

Correlations between $\dot{\mathrm{VO}}_{2 \text { peak }}$ and physical activity level, time since transplantation, and HRQoL are presented in Figure 2. There was a moderate correlation between $\dot{\mathrm{V}} \mathrm{O}_{2 \text { peak }}$ and physical activity level (measured by counts per minute) and between $\dot{\mathrm{VO}}_{2 \text { peak }}$ and the physical aspect of HRQoL (measured by the SF-36 physical component summary score). There was a negligible correlation between $\dot{\mathrm{VO}}_{2 \text { peak }}$ and time since transplantation, and between $\dot{\mathrm{VO}}_{2 \text { peak }}$ and the mental aspect of HRQoL (measured by the SF-36 mental component summary score). Univariate and multivariable analyses for associations with $\dot{\mathrm{VO}}_{2 \text { peak }}$ are presented in Table 3. Univariate regression analysis indicated that sex, age, BMI, physical activity, the physical aspect of HRQoL, $\mathrm{FEV}_{1}$, and $\mathrm{DL}_{\mathrm{CO}}$ were significantly associated with $\dot{\mathrm{V}} \mathrm{O}_{2 \text { peak. }}$. The final multivariable regression model showed that BMI, physical activity, $\mathrm{FEV}_{1}$, sex, and $\mathrm{Hb}$ together accounted for $73 \%$ of the variability in $\dot{\mathrm{V}}_{2 \text { peak. }}$

\section{Discussion/Conclusion}

We found that only 3 out of 54 BLTx recipients had normal cardiorespiratory fitness $\left(\dot{\mathrm{V}}_{2 \text { peak }}\right)$ and that physical activity level was low. CPET results revealed that both deconditioning and cardiopulmonary factors caused exercise intolerance. Forty-three patients (86\%) did not meet the WHO's physical activity recommendations, and daily sedentary time was $30 \%$ greater than in a healthy Norwegian population. We further demonstrated that $\dot{\mathrm{V}} \mathrm{O}_{2 \text { peak }}$ is associated with physical activity level after BLTx.

Our results showed that $\mathrm{VO}_{2 \text { peak }}$ is low among BLTx recipients and that considerable exercise intolerance persists after BLTx. This is in line with findings from previous studies showing minimal increase in $\dot{\mathrm{VO}}_{2 \text { peak }}$ after BLTx and does not match the large improvement in pulmonary function $[31,32]$. However, in our population, low cardiorespiratory fitness was caused by both deconditioning and cardiopulmonary limitations. The high number $(n=29)$ of patients with cardiopulmonary limitations to exercise was somewhat surprising, as chronic muscle deconditioning and skeletal muscle abnormalities have been proposed as the main exercise-limiting factors in previous studies [32]. 
Patients who were deconditioned had low oxygen pulse, indicating poor stroke volume, but normal gas exchange and adequate breathing reserve. A similar combination has been observed in deconditioned individuals in other clinical settings [24]. For such patients, exercise therapy may be especially beneficial.

A low breathing reserve raises the possibility of ventilatory limitation to exercise [23]. One-fourth of the patients were ventilatory limited. As expected, patients with ventilatory limitations also had low $\mathrm{HR}_{\text {peak }}$ and did not reach the end-criteria for maximal effort (high respiratory exchange ratio and blood lactate concentration). Ventilatory limitation to exercise could in most cases be explained by respiratory pathology. Some of the patients had experienced severe loss of pulmonary function $\left(\mathrm{FEV}_{1}\right)$ due to CLAD or other postoperative complications. Ventilatory limitation has not been reported in earlier studies $[8,31,33]$, possibly due to missing data on patients with postoperative lung complications, early CPET termination, or the use of a different exercise mode. The exercise mode may have played an important role in detecting ventilatory limitations in the present study. Our patients were tested by uphill walking on a treadmill, which is a more functional way of moving than cycle ergometer and is known to elicit $10-20 \%$ higher $\mathrm{VO}_{2 \text { peak }}$ because larger muscle groups are involved [24]. Treadmill testing therefore places a higher demand on the cardiopulmonary system. The higher $\mathrm{HR}_{\text {peak }}$ reported in our study compared to that in previous BLTx studies also supports this possibility $[6,7,33]$.

An elevated $\mathrm{VE} / \mathrm{VCO}_{2}$ slope, demonstrating excessive ventilation relative to metabolic demand, is normally caused by increased dead space ventilation (ventilationperfusion mismatch) [34]. An elevated $\mathrm{VE} / \mathrm{VCO}_{2}$ slope was seen in many of our patients. This finding was observed in patients with and without known postoperative lung complications and independent of elapsed time since transplantation. Our findings are in line with those reported by Schwaiblmair et al. [33], who described ventilation-perfusion mismatch in patients 3 months after BLTx. However, in contrast to a study by Habedank et al. [12] suggesting that ventilatory inefficiency improves rapidly after BLTx and meets normal values within 24 months, we observed that ventilatory inefficiency persists up to 5 years after BLTx.

Previous studies have shown reduced levels of physical activity after LTx $[2,35,36]$. Our study confirms this finding and further demonstrates that $\mathrm{V}_{2 \text { peak }}$ is moderately associated with physical activity after BLTx. In order to improve $\dot{\mathrm{V}}_{2 \text { peak }}$ and reduce the risk of certain noncom- municable diseases (cardiovascular disease, diabetes, osteoporosis, various cancers, and depression), the WHO recommends at least $150 \mathrm{~min}$ of moderate-to-vigorous physical activity, performed in bouts lasting at least 10 min per week [28]. The vast majority of BLTx recipients in our study did not meet this criterion. Importantly, we found that higher $\dot{\mathrm{VO}}_{2 \text { peak }}$ was associated with higher physical activity level, and patients meeting the WHO recommendations for physical activity had a significantly higher $\dot{\mathrm{V}}_{2 \text { peak }}$ than those who did not. In future studies, reporting comparison between national standards and the WHO recommendations may be useful since it will enable comparisons across different centers.

With respect to possible predictors of $\dot{\mathrm{V}}_{2 \text { peak, }}$ we observed a high prevalence of anemia, which is known to affect $\dot{\mathrm{V}} \mathrm{O}_{2 \text { peak }}$ negatively $[23,37]$. Anemia alone is unlikely to fully explain the low $\dot{\mathrm{VO}}_{2 \text { peak }}$, given that the majority only had mild anemia but still had substantial impairment in $\dot{\mathrm{V}}_{2 \text { peak }}$ [37]; however, multivariable analysis suggests that it may be an important contributor. The causes of anemia in our study population are likely multiple and may include adverse effects of immunosuppressive medications; nonetheless, it is reasonable to speculate that some patients may have modifiable causes of anemia, such as iron deficiency, for which treatment may help improve cardiorespiratory fitness and physical activity.

Another contributor to lower $\dot{\mathrm{V}} \mathrm{O}_{2 \text { peak }}$ was higher BMI. Weight gain after LTx is common, and median weight gain of $10 \%$ in the first year after LTx has been observed [38]. The high number of overweight or obese patients in our study is a matter of concern, as it may have an impact on $\dot{\mathrm{V}} \mathrm{O}_{2 \text { peak }}$ and morbidity. This finding, together with the low levels of physical activity, highlights the need to develop targeted exercise interventions after BLTx and assess their effect on patient-centered outcomes in clinical trials. Females in the present study had significantly higher $\mathrm{VO}_{2 \text { peak }} \%$ of predicted than males, which is interesting as female recipients have shown significantly improved survival over 5 years compared to males [39], and higher $\dot{\mathrm{V}} \mathrm{O}_{2 \text { peak }}$ is associated with improved survival in the general population [4]. To our knowledge, no study has assessed $\mathrm{V}_{2 \text { peak }}$ as a predictor of mortality after LTx, and its relevance should be investigated in future prospective studies. We recognize that the impact of gender on $\dot{\mathrm{V}}{ }_{2 \text { peak }}$ might be biased by the higher prevalence of CLAD among males in this study (6 of 7 patients with CLAD were males). However, exclusion of the 7 patients diagnosed with CLAD in the analyses did not eliminate the significant gender difference. 
Limitations of our study include the cross-sectional design, which does not permit us to define causal relationships. However, our large sample size relative to prior studies and the complexity of our physiological assessments nonetheless allow for a thorough analysis of the factors associated with $\dot{\mathrm{VO}}_{2 \text { peak }}$ and physical activity in BLTx recipients. The causes of exercise intolerance after BLTx are incompletely understood, but impaired oxidative function of skeletal muscle has previously been recognized as a potentially important factor $[10,40]$. We did not have the opportunity to formally assess the oxidative function of skeletal muscle, for example with muscle biopsies.

In conclusion, low cardiorespiratory fitness was observed in nearly all BLTx recipients. Deconditioning and cardiopulmonary factors limiting exercise were equally common. Only a small minority met standard recommendations for physical activity. Lower physical activity levels were associated with lower cardiorespiratory fitness. Our findings highlight the need to develop targeted exercise interventions after BLTx. CPET appears to identify a deconditioned subgroup of BLTx recipients for whom exercise training may be especially beneficial.

\section{Acknowledgement}

The authors would like to thank physiologist Stian Roterud for technical assistance during the cardiopulmonary exercise testing and Liv Ingunn Bjoner Sikkeland for editing tables and figures.

\section{Statement of Ethics}

Ethical approval was obtained from the Regional Committee for Medical and Health Research Ethics (REK South-East, No. 2017/399). The authors have no ethical conflicts to disclose.

\section{Disclosure Statement}

The authors have no conflicts of interest to declare.

\section{Funding Sources}

The study was funded by research grants from the Division of Cardiovascular and Pulmonary Diseases at Oslo University Hospital. The project has not received financial support from any commercial source, and the authors have no financial interests which could potentially create a conflict of interest.

\section{Author Contributions}

E.E., M.T.D., M.B.L., and J.S.K. designed the study. M.U. was responsible for data collection, statistical analyses, and drafting the manuscript. B.H.H. contributed to the analyses of the accelerometer data. The manuscript was critically reviewed and approved by all authors.

\section{References}

1 Yusen RD, Edwards LB, Dipchand AI, Goldfarb SB, Kucheryavaya AY, Levvey BJ, et al.; International Society for Heart and Lung Transplantation. The Registry of the International Society for Heart and Lung Transplantation: Thirty-third Adult Lung and HeartLung Transplant Report-2016; Focus Theme: Primary Diagnostic Indications for Transplant. J Heart Lung Transplant. 2016 Oct; 35(10):1170-84.

2 Langer D, Gosselink R, Pitta F, Burtin C, Verleden G, Dupont L, et al. Physical activity in daily life 1 year after lung transplantation. J Heart Lung Transplant. 2009 Jun;28(6):572-8.

3 Blair SN. Physical inactivity: the biggest public health problem of the 21 st century. Br J Sports Med. 2009 Jan;43(1):1-2.

4 Ross R, Blair SN, Arena R, Church TS, Després JP, Franklin BA, et al.; American Heart Association Physical Activity Committee of the Council on Lifestyle and Cardiometabolic Health; Council on Clinical Cardiology; Council on Epidemiology and Prevention; Council on Cardiovascular and Stroke
Nursing; Council on Functional Genomics and Translational Biology; Stroke Council. Importance of Assessing Cardiorespiratory Fitness in Clinical Practice: A Case for Fitness as a Clinical Vital Sign: A Scientific Statement From the American Heart Association. Circulation. 2016 Dec;134(24):e653-99.

5 Myers J, McAuley P, Lavie CJ, Despres JP, Arena R, Kokkinos P. Physical activity and cardiorespiratory fitness as major markers of cardiovascular risk: their independent and interwoven importance to health status. Prog Cardiovasc Dis. 2015 Jan-Feb;57(4):306-14.

6 Miyoshi S, Trulock EP, Schaefers HJ, Hsieh CM, Patterson GA, Cooper JD. Cardiopulmonary exercise testing after single and double lung transplantation. Chest. 1990 May; 97(5):1130-6.

7 Williams TJ, Patterson GA, McClean PA, Zamel N, Maurer JR. Maximal exercise testing in single and double lung transplant recipients. Am Rev Respir Dis. 1992 Jan;145(1):101-5.

8 Levy RD, Ernst P, Levine SM, Shennib H, Anzueto A, Bryan CL, et al. Exercise performance after lung transplantation. J Heart Lung Transplant. 1993 Jan-Feb;12(1 Pt 1):27-33.

9 Orens JB, Becker FS, Lynch JP 3rd, Christensen PJ, Deeb GM, Martinez FJ. Cardiopulmonary exercise testing following allogeneic lung transplantation for different underlying disease states. Chest. 1995 Jan;107(1):144-9.

10 Lands LC, Smountas AA, Mesiano G, Brosseau L, Shennib H, Charbonneau M, et al. Maximal exercise capacity and peripheral skeletal muscle function following lung transplantation. J Heart Lung Transplant. 1999 Feb;18(2):113-20.

11 Reinsma GD, ten Hacken NH, Grevink RG, van der Bij W, Koëter GH, van Weert E. Limiting factors of exercise performance 1 year after lung transplantation. J Heart Lung Transplant. 2006 Nov;25(11):1310-6.

12 Habedank D, Ewert R, Hummel M, Dandel M, Habedank F, Knosalla C, et al. The effects of bilateral lung transplantation on ventilatory efficiency, oxygen uptake and the right heart: a two-yr follow-up. Clin Transplant. 2011 Jan-Feb;25(1):E38-45. 
13 WHO. Haemoglobin concentrations for the diagnosis of anaemia and assessment of severity. Vitamin and Mineral Nutrition Information System. Available from: http://www. who.int/vmnis/indicators/haemoglobin.pdf

14 WHO. Obesity: preventing and managing the global epidemic. Report of a WHO consultation. World Health Organ Tech Rep Ser. 2000; 894:i-xii.

15 Meyer KC, Raghu G, Verleden GM, Corris PA, Aurora P, Wilson KC, et al.; ISHLT/ATS/ ERS BOS Task Force Committee; ISHLT/ ATS/ERS BOS Task Force Committee. An international ISHLT/ATS/ERS clinical practice guideline: diagnosis and management of bronchiolitis obliterans syndrome. Eur Respir J. 2014 Dec;44(6):1479-503.

16 Miller MR, Hankinson J, Brusasco V, Burgos F, Casaburi R, Coates A, et al.; ATS/ERS Task Force. Standardisation of spirometry. Eur Respir J. 2005 Aug;26(2):319-38.

17 Graham BL, Brusasco V, Burgos F, Cooper BG, Jensen R, Kendrick A, et al. 2017 ERS/ ATS standards for single-breath carbon monoxide uptake in the lung. Eur Respir J. 2017 Jan;49(1):pii:1600016.

18 Quanjer PH, Stanojevic S, Cole TJ, Baur X, Hall GL, Culver BH, et al.; ERS Global Lung Function Initiative. Multi-ethnic reference values for spirometry for the 3-95-yr age range: the global lung function 2012 equations. Eur Respir J. 2012 Dec;40(6):1324-43.

19 Stanojevic S, Graham BL, Cooper BG, Thompson BR, Carter KW, Francis RW, et al. Global Lung Function Initiative TLCO working group; Global Lung Function Initiative (GLI) TLCO. Official ERS technical standards: global Lung Function Initiative reference values for the carbon monoxide transfer factor for Caucasians. Eur Respir J. 2017 Sep; 50(3):1700010.

20 Balke B, Ware RW. An experimental study of physical fitness of Air Force personnel. U S Armed Forces Med J. 1959 Jun;10(6):675-88.

21 Edvardsen E, Hansen BH, Holme IM, Dyrstad SM, Anderssen SA. Reference values for cardiorespiratory response and fitness on the treadmill in a 20 - to 85 -year-old population. Chest. 2013 Jul;144(1):241-8.
22 Edvardsen E, Hem E, Anderssen SA. End criteria for reaching maximal oxygen uptake must be strict and adjusted to sex and age: a cross-sectional study. PLoS One. 2014 Jan; 9(1):e85276.

23 Wasserman K. Principles of Exercise Testing and Interpretation: Including Pathophysiology and Clinical Applications: Wolters Kluwer Health/Lippincott Williams \& Wilkins; 2012.

24 ATS/ACCP Statement on Cardiopulmonary Exercise Testing. ATS/ACCP Statement on Cardiopulmonary Exercise Testing. Am J Respir Crit Care Med. 2003;167(2):211-77.

25 Myers J, Tan SY, Abella J, Aleti V, Froelicher VF. Comparison of the chronotropic response to exercise and heart rate recovery in predicting cardiovascular mortality. Eur J Cardiovasc Prev Rehabil. 2007 Apr;14(2): 215-21.

26 Hansen BH, Kolle E, Dyrstad SM, Holme I, Anderssen SA. Accelerometer-determined physical activity in adults and older people. Med Sci Sports Exerc. 2012 Feb;44(2):266-72.

27 Troiano RP, Berrigan D, Dodd KW, Mâsse LC, Tilert T, McDowell M. Physical Activity in the United States Measured by Accelerometer. Med Sci Sports Exerc. 2008 Jan;40(1): 181-8.

28 World Health Organization. Global Recommendations on Physical Activity for Health. Geneva: WHO; 2010.

29 Garratt AM, Stavem K. Measurement properties and normative data for the Norwegian SF36: results from a general population survey. Health Qual Life Outcomes. 2017 Mar;15(1): 51.

30 Mukaka MM. Statistics corner: A guide to appropriate use of correlation coefficient in medical research. Malawi Med J. 2012 Sep; 24(3):69-71.

31 Bartels MN, Armstrong HF, Gerardo RE, Layton AM, Emmert-Aronson BO, Sonett JR, et al. Evaluation of pulmonary function and exercise performance by cardiopulmonary exercise testing before and after lung transplantation. Chest. 2011 Dec;140(6):1604-11.
32 Dudley KA, El-Chemaly S. Cardiopulmonary exercise testing in lung transplantation: a review. Pulm Med. 2012;2012:237852.

33 Schwaiblmair M, Reichenspurner H, Müller C, Briegel J, Fürst H, Groh J, et al. Cardiopulmonary exercise testing before and after lung and heart-lung transplantation. Am J Respir Crit Care Med. 1999 Apr;159(4 Pt 1):127783.

34 Guazzi M, Adams V, Conraads V, Halle M, Mezzani A, Vanhees L, et al.; European Association for Cardiovascular Prevention \& Rehabilitation; American Heart Association. EACPR/AHA Scientific Statement. Clinical recommendations for cardiopulmonary exercise testing data assessment in specific patient populations. Circulation. 2012 Oct;126(18): 2261-74.

35 Wickerson L, Mathur S, Singer LG, Brooks D. Physical activity levels early after lung transplantation. Phys Ther. 2015 Apr;95(4):51725.

36 Bossenbroek L, ten Hacken $\mathrm{NH}$, van der Bij W, Verschuuren EA, Koëter GH, de Greef $\mathrm{MH}$. Cross-sectional assessment of daily physical activity in chronic obstructive pulmonary disease lung transplant patients. J Heart Lung Transplant. 2009 Feb;28(2):14955.

37 Agostoni P, Salvioni E, Debenedetti C, Vignati C, Cattadori G, Contini M, et al. Relationship of resting hemoglobin concentration to peak oxygen uptake in heart failure patients. Am J Hematol. 2010 Jun;85(6):414-7.

38 Singer LG, Brazelton TR, Doyle RL, Morris RE, Theodore J; International Lung Transplant Database Study Group. Weight gain after lung transplantation. J Heart Lung Transplant. 2003 Aug;22(8):894-902.

39 Loor G, Brown R, Kelly RF, Rudser KD, Shumway SJ, Cich I, et al. Gender differences in long-term survival post-transplant: A single-institution analysis in the lung allocation score era. Clin Transplant. 2017 Mar; 31(3):e12889.

40 Wang XN, Williams TJ, McKenna MJ, Li JL, Fraser SF, Side EA, et al. Skeletal muscle oxidative capacity, fiber type, and metabolites after lung transplantation. Am J Respir Crit Care Med. 1999 Jul;160(1):57-63. 